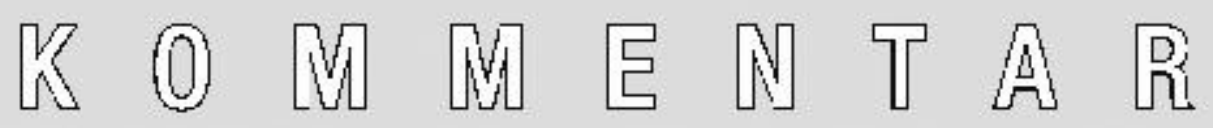

\title{
Til fødselsdag med amerikansk sociologi - American Sociological Association i 100 år
}

2005 er året, hvor den amerikanske sociologforening - ASA - fejrer sin 100 års fødselsdag. Foreningen blev nemlig startet allerede i 1905, hvor den stiftende generalforsamling blev afholdt på John Hopkins Universitetet i Baltimore.

Her 100 år senere er organisationen - og for så vidt også amerikansk sociologi - stadig i live. Med sine 15.000 medlemmer er ASA den største sociologiske forening i verden. Og med mere end 5.000 kongresdeltagere til den amerikanske sociologkongres i Philadelphia i august 2005 er det kun ISA's verdenssociologkongres, der kommer op på tilnærmelsesvis samme deltagerantal. Der er naturligvis tale om et megaarrangement, hvor sociologiske teorier og genstandsfelter af enhver art er til debat og diskussion.

Følgende artikel er - på baggrund af deltagelse i kongressen - et forsøg på at indfange nogle af tendenserne $i$ amerikansk sociologi og nogle af begivenhederne på kongressen. Men hverken på en repræsentativ eller dækkende facon. Det lader sig naturligvis ikke gøre. Til gengæld er hensigten at sætte fokus på amerikansk sociologis historie (igen dog uden på nogen måde at være dækkende eller repræsentativ) og aktuelle status i forhold til udvalgte områder.

Amerikansk sociologi som sådan er dog mere end de 100 år, som den faglige organisation ASA har på bagen. American Journal of Sociology blev stiftet allerede i 1890 og det første kursus i sociologi ved et amerikansk universitet daterer sig til 1879 og var om Herbert Spencer (Calhoun \& Truster 2005: B7).

I dag er sociologien en fast etableret videnskabelig disciplin i universitetsog collegeverdenen i USA på linie med økonomi og statskundskab. Og med en omfattende årlig produktion af sociologiske forskere.

Ser man nærmere på ASA's historie og deres formænd, vil man få øje på at en lang række af det 20. århundredes store sociologer. Erving Goffmann (19221982), Talcott Parsons (1902-1979), Louis Wirth (1897-1952), Herbert Blumer (1900-1987), Pitirim A. Sorokin (1889-1968), Peter Blau (1918-2002), Robert K. Merton (1910-2003), James Coleman (1926-1995) og mange flere har qua deres 
akademiske meriter været med til at sætte dagsordenen ikke kun i amerikansk, men også i europæisk sociologi (Rosich 2005).

\section{Sociologien som social bevægelse}

Sociologiens opkomst i det amerikanske samfund omkring slutningen af 1800tallet var i vidt omfang relateret til forskellige former for sociale reformbevægelser. Ofte reformbevægelser med stærke religiøse bånd fx til Kvæker-bevægelsen.

American sociology emerged as a distinct scholarly discipline out of the social science movement of the nineteenth century. That movement entailed more than university-based research and teaching; it was more than an academic curriculum. It included philanthropic works, communes, settlement houses, and social activism. (Blasi 2005:1).

Mange sociologiske overvejelser var derfor i slutningen af 1800-tallet og begyndelse af 1900-tallet knyttet til diskussioner om reformeringen af bestemte "problematiske" forhold i det amerikanske samfund. Fx i relation til konflikterne mellem sorte og hvide. Sociologiens rolle var i den sammenhæng at bidrage med videnskabeligt funderede løsninger på samfundets problemer. Sociologien skulle i den forstand bidrage til det amerikanske samfunds generelle udvikling, eller som det formuleres hos Schwartz: "Among the first generation of american sociologists, social evolution was the preeminent perspective". (Schwartz 1987:2).

For nogle var anknytningen til de sociale bevægelser et afgørende tegn på diskvalificering af sociologien. Skulle sociologien manifestere sig som rigtig videnskab var det afgørende, at relationen til reformbevægelserne blev lagt på hylden. Fokus skulle være på, hvordan det sociale er, ikke på hvordan det sociale bør eller kunne være.

En af fortalerne for, at sociologien skulle udvikle sig til "rigtig videnskab", var Robert E. Park (1864-1944), en af ankermændene i Chicagoskolen.

"Robert E. Park played a central role in defining sociology as a natural science. He imagined sociologists as unbiased and unaffected by the human behaviour they studied: "Their role was to be "the calm, detached scientist who investigates race relations with the same objectivity and detachment with which the zoologist dissects the potato bug" (Ernest W. Burgess cited by Matthews (1977:116). This perspective attacked the earlier intention of many founders of sociology who envisioned sociology as a moral science. These founders studied society to learn how to alleviate poverty, create social justice, and enhance human freedom.... (Deegan 2005:18). 


\section{Chicago skolen - en franskmands erfaringer}

Efter første verdenskrig blev et af de centrale omdrejningspunkter i amerikansk sociologi udviklet i Chicago. Og Chicagoskolen - som den senere blev døbt - skulle vise sig at blive en af de langtidsholdbare traditioner i amerikansk sociologi. Ernest W. Burgess (1886-1966), Robert E. Park (1864-1944) og Louis Wirth (1897-1952) var nogle af de centrale navne i traditionen og omdrejningspunktet for deres forskning var studiet af byen Chicago. Forestillingen om byen som "meltingpoint" mellem forskellige etniske grupper blev skabt gennem disse studier.

Chicagoskolen prægede amerikansk sociologi gennem deres sociologiske lærebøger og ikke kun gennem deres studier af byen og byens liv. Burgess og Park skrev således "Introduction to the Science of Sociology" (1924), der blev en meget anvendt sociologisk lærebog (Hamilton 2003). Fokus var her på udviklingen af sociologi som videnskab på linie med andre videnskaber.

George Herbert Mead (1863-1931) var også i store dele af sit akademiske liv tilknyttet Universitetet i Chicago og blev eksponent for udviklingen af den symbolske interaktionisme. Hos Mead var "selvets" og individets konstituering, i centrum for analysen ${ }^{1}$. Hermed blev der åbnet op for en lang tradition $i$ amerikansk sociologi, hvor individet og individets interaktioner med andre individer (og institutionaliseringen heraf), blev gjort til genstand for analyse. "Selvet" blev set som skabt netop gennem relationen til andre individer. Samfundets aktører var ikke kun "agenter" i de sociale institutioner (som hos Durkheim). I amerikansk sociologi er denne tradition bl.a. videreudviklet hos Herbert Blumer ${ }^{2}$ og Erving Goffmann.

I takt med at Chicagoskolen etablerede sig som sociologisk forskningsinstitution tiltrak de også europæiske forskere, der ønskede at lære om deres studier. På ASA-kongressen (session 249) ${ }^{3}$ holdt Suzanne Vromen, Professor Emerita i Sociologi ved Brad College, indlæg om en af dem, der besøgte Chicagos sociologiske institut i 1930 og som skrev om besøget. Det var den franske sociolog Maurice Halbwachs (1877-1945), daværende professor i sociologi ved universitetet i Strassbourg og den første professor i sociologi ved de akademiske institutioner i Frankrig (Vromen 2005:323).

Halbwachs, der var en trofast Durkheimianer og som derfor anså statistikken som grundlaget for den sociologiske videnskabelighed, blev på én gang begejstret og forfærdet over, hvad han oplevede i Chicago.

Begejstringen knyttede an til det sociologiske instituts ressourcer og gå-påmod. Mængden af maskiner til brug for talbehandling oversteg langt, hvad standarderne i Frankrig kunne leve op til på den tid. Og miljøet summede af liv og aktivitet; ofte i sådant et omfang at Halbwachs blev ganske udmattet.

Not only was Halbwachs stuck by the organization and the resources of the Department of Sociology; he was also impressed by the desire for 
social action fueled by sociological knowledge, a kind of applied and practical sociology. (Vromen 1995:328-29).

Instituttet havde en lang tradition for at involvere det omgivende samfund $\mathrm{i}$ den sociologiske forskning og havde en omfattende kontakt til de byområder, der blev studeret.

Forfærdelsen knyttede an til flere forhold. For det første undervisningsbyrden. "These americans know how to exploit you" skrev han i et brev til sin mor. Og til sin kone skrev han, at han havde forestået undervisningen af 95 klasser på to måneder, "more than in a year in Strasbourg. They have a susperstition of quantity". (Vromen 1995:327).

For det andet studenterinvolveringen. Studenterne blev spurgt om deres ønsker og holdning til kurserne. Instituttet præsenterede studenterrepræsentanter "... with the new programs and to ask them what they would like added or modified. They argue for two hours, unheatedly, very naturally, and they will do it again next month". (Brev fra Halbwachs, citeret fra Vromen 1995: 328). Helt uhørt i et fransk akademisk system.

Og endelig og for det tredje var forfærdelsen rettet mod den sociologiske forsknings metoder. Det var ikke den kalkulerende statistiske analyse udfoldet $\mathrm{i}$ universitetets trygge ramme, der var i højsædet i Chicago, men derimod det involverende, opsøgende feltarbejde.

On another occation he expressed his disdain, or rather his fear of fieldwork, in the following terms: "They are affraid of nothing. Burgess wanted to take me to a place where one meets assassins. I found that stupid and I refused. It is perhaps I who am an idiot..." (Vromen 2005:330).

Grundlæggende var skepsisen dog ikke baseret på frygt men på kritik af det metodiske grundlag. For Halbwachs mindede Chicago-skolens monografier mere om journalistik end om videnskab. Interessant, underholdende og indsigtsfuldt, men ikke videnskab.

\section{De sociologiske forhåbninger - sociologiens gyldne år ${ }^{4}$}

1940'erne og 1950'erne var på sin vis amerikansk sociologis "gyldne" årtier. Det var i denne periode, at tiltroen til sociologiens udviklingspotentialer blomstrede, hvilket ikke mindst skete i tilknytning til Harvard University og Talcott Parsons" udvikling af sin "theory of social action" og senere "theory of social system". Og det var i samme periode, Max Weber (1864-1920) blev introduceret i amerikansk sociologi. Det var først i løbet af 1940'erne, at amerikansk sociologi for alvor fik kendskab til Weber, bl.a. som følge af Parsons "The Structure of Social Action“ (1937), men også som følge af tilstedeværelsen af en række europæiske samfundsforskere, som flygtede fra Hitlers Tyskland til USA. 
De medbragte Weber som en del af deres sociologiske bagage, og som det bemærkes af Hamilton:

It is perhaps difficult for contemporary sociologists to imagine a "world without Weber", but the man's impact in the United States came more than four decades after publication of his best-known work, "The protestant Ethic and the Spirit of Capitalism" (Hamilton 2003:284).

Professor Stephen Turner, University of South Florida, fremhævede på et seminar på ASA-kongressen (session 88), hvordan sociologien i dens gyldne periode ikke var bange for at fremhæve egne evner. 1950'ernes sociologi havde som sit direkte mål at udvikle den sociologiske videnskabelighed i en sådan grad, at sociologien kunne bidrage med løsningen af samfundsmæssige problemer. Raceproblemet skulle løses gennem holdningsændringer. Og sociologien skulle sammen med socialpsykologien bidrage til den videnskabelige indsats over for upassende holdninger.

Tilsvarende blev sociologien $i$ vidt omfang institutionaliseret i det amerikanske samfund. Sociologi blev en del af mange college-uddannelser og tusinder af amerikanske studerende fik herigennem kendskab til disciplinen. Og som det hedder hos Sibley i en bog om perspektiverne i sociologiuddannelsen i det amerikanske samfund:

Sociology has been trying for many decades to come of age as a science and as a professional field. It can be said now to be in a late stage of adolescence, at a time of potentially rapid maturation (Sibley 1963:16).

Samtidigt blev den sociologiske litteratur gjort til en del af den amerikanske mainstream og masselitteratur. Sociologiske værker kunne købes i kiosker, på jernbaner og andre steder fjernt fra universiteternes hellige haller (Gouldner 1970:4).

Parallelt med at sociologien skulle bidrage til udviklingen af det moderne samfund, var ambitionen også at udvikle sociologien til en abstrakt og universel videnskab om samfunds udvikling. Parsons bidrog til denne udvikling med systemteorien. Hvor sociologien i USA tidligere havde haft et individorienteret og interaktionistisk perspektiv på det sociale felt, blev der med Parsons sat fokus på samfundet som samlet social orden.

Talcott Parsons is the major figure in the transition from the predominantly individualistic social psychological theory of early American sociology to its post-war holistic, antipsychological standpoint. Parsons was the first American sociologists to develop a coherent theory of society 
conceived as a whole in opposition to the dominant mode of anti-theoretical sociological empiricism (Swingewood 1991:228-229).

Samtidigt var Parsons også en engageret og delagtiggørende underviser ved Harvard. Et forhold mange senere sociologer har opfattet som betydningsfuldt for deres egen karriere. Neil Smelser, Professor emeritus ved University of California skriver fx følgende om sit eget ophold ved Harvard:

He (csj: Parsons) was the leader and the symbol of the Social Relations Department, then in the early, heady, pioneering phase of its existence. In those lectures he also outlined his developing theoretical thinking (to appear two years later in "Toward a General Theory of Social Action") and I was left breathless by his brilliance and above all his theoretical comprehensiveness (Smelser 2000:8-9).

På kongressen (session 88) blev det også fremhævet, at 1930'ernes amerikanske sociologi synes bemærkelsesværdigt underrepræsenteret i nutidig amerikansk sociologi. Professor Patricia Lengermann fra Georg Washington University antydede, at det måske var, fordi i hvert fald dele af 1930'ernes sociologi i for høj grad var inspireret af tanker - om bl.a. eugenetik - til, at nutidens sociologer helt kan passe det ind i deres egen fortolkning af det sociologiske projekt. ASA's formand i 1936, Henry Pratt Fairchild (1880-1956), skrev bl.a.:

The birth control movement is the only active force in modern life devoted to the achievement of this objective [population control] on the basis of rational self direction, and its limited extension results in the disproportionate increase of those social groups who are least able to support large families in an adequate degree of comfort, and least likely to contribute to the upbuilding and advancement of society by unrestrained increments to the population ${ }^{5}$. (Citeret fra ASA's hjemmeside (www.asanet.org)).

Synspunkter der - om end i noget stærkere form - også kunne høres andre steder i 1930'erne.

\section{Wright Mills og Sorokin - enegængere i amerikansk sociologi}

Harvard University var imidlertid ikke kun præget af Parsons og Parsons' teorier. Det sociologiske institut på Harvard var oprindeligt blevet etableret $\mathrm{i}$ 1931 under ledelse af den russiske emigrant Pitirim A. Sorokin.

Edward A. Tiryakian, fra Duke University, præsenterede på ASA-kongressen (session 522) en række iagttagelser om Sorokin og udviklingen i amerikansk sociologi under overskriften: To enegængere i amerikansk sociologi. Den 
første enegænger var Pitirim A. Sorokin, den anden C. Wright Mills.

På Harvard kom Parsons teorier til at dominere trods Sorokins status som leder af instituttet. Og det blev Parsons, som lokkede studenterne til sig. Robert K. Merton (1910-2003) - en af Sorokins elever - arbejdede videre med udgangspunkt i Parsons strukturfunktionalisme. Og Kingsley Davis (1908-1997) endte ligeledes i Parsons favn. Kingsley Davis blev især berømt for arbejdet med den sociale lagdeling (den tradition som Svalastoga udviklede på Sociologisk Institut i Danmark). Sorokin blev i den forstand en udgrænset og enegængeragtig skikkelse på Harvard. Parsons overtog for alvor instituttet $\mathrm{i}$ midten af fyrrene, hvor The Department of Social Relations blev etableret under Parsons ledelse.

Wright Mills blev hentet til Columbia University af Paul Lazarsfeldt (19011976), der, mere end nogen anden, er blevet eksponent for den oprindelige udvikling af kvantitativ sociologi i USA. Både Wright Mills og Sorokin beskæftigede sig bl.a. med spørgsmålet om social mobilitet og social stratifikation om end med hver deres tilgang. Sorokin havde lavet analyser af urbaniseringens og industrialiseringens betydning for opbruddet i den sociale struktur. Vandringen fra land til by førte til underminering af de rurale sociale strukturer og muliggjorde helt nye former for social mobilitet i det moderne samfund. Wright Mills havde analyseret, hvordan nye typer af magtstrukturer underminerede den mulige social mobilitet og cementerede de sociale strukturer. Dette var hovedsynspunktet i "The Power Elite".

Wright Mills var som bekendt massiv i sin kritik af Talcott Parsons i "The Sociological Imagination“ (1959), hvor Parsons udvikling af abstrakte sociologiske kategorier blev kritiseret for at være indholdstomme og uden historisk sans. Kritikken skulle dog ifølge Tiryakian også ses i lyset af, at Parsons havde været tilsvarende massiv i sin kritik af Wright Mills "The Power Elite". Der var derfor - som det blev formuleret af Tiryakian - i et vist omfang tale om "pay back time".

Ifølge Tiryakian skulle Wright Mills ved flere lejligheder have givet udtryk for, at Sorokin havde været en central inspirationskilde i forbindelse med arbejdet med "The Sociological Imagination". Sorokin skulle til dette have repliceret, at det da glædede ham, men at han i så fald gerne havde set en reference til ham selv. Inspirationen fremgik nemlig ikke af bogen.

For både Wright Mills og Sorokin blev det dog tallenes meningsløshed og tyranni, der blev omdrejningspunktet for hver deres kritik af 1950'ernes amerikanske sociologi.

Trods de interne trakasserier i den akademiske verden blev Wright Mills "The Sociological Imagination" et slags startskud for opkomsten af det nye venstre $\mathrm{i}$ amerikanske akademiske cirkler.

"C. Wright Mills both analyzed and satirized the opposition of "grand theory" and "abstracted empiricism" in "The Sociological Imagination". His point was how dualism obscured lack of critical attention to public 
problems. .... Mills' book appeared in 1959 and would shape the rise of the New Left" (Calhoun \& Truster 2005:B7).

\section{8}

1960'erne forandrede på mange måder sociologien i USA. Vietnam-krigen, hippiebølgen, kvindefrigørelsen og borgerrettighedsbevægelsen var blandt de begivenheder, der satte deres mærke ikke kun i det amerikanske samfund i almindelighed, men i sociologien i særdeleshed. Det betød dels et opgør med Parsons` abstrakte systemteori og dels et opgør med den værdifrie og samfundsneutrale forskning. Og det betød også opgør inden for den amerikanske sociologforening.

ASA oplevede i 1968 markant kritik fra studenteroprørerne, og ved årsmøderne i 1968 og 1969 var der en række parallelle protestarrangementer, der fremhævede, hvordan amerikansk sociologi først og fremmest var præget af hvide middelklasse mænds interesser og synspunkter. Kvindegrupper, grupper af sorte og modstandere af Vietnam-krigen argumenterede for, at ASA i højere grad skulle give slip på den påståede samfundsmæssige neutralitet. Og ASA svarede dels med en række initiativer, der skulle imødekomme kritikken af kvinder og sortes svage positioner i det akademiske miljø (Rhoades 1981:60 ff.), men også med kritik af protestaktionerne.

In 1969, Council "censured and condemned those persons - members and non-members - who disrupted the presidential adress and the plenary session" that year in San Francisco with an anti-war demonstration (Rhoades 1981:60).

På det teoretiske plan var Wright Mills ikke den eneste, som var med til at bane vejen for udviklingen af et mere samfundskritisk sociologisk perspektiv på analysen af det amerikanske samfunds sociale orden. Alvin W. Gouldner (19201980) skrev i 1970 bogen The Comming Crisis of Western Sociology, der indeholdt et opgør med Parsons's strukturfunktionalisme og denne traditions påståede neutralitet over for forskellige samfundsmæssige interesser. Gouldner argumenterede for, at når Parsons advokerede for, at sociologien skulle bidrage til at stabilisere den sociale orden i det amerikanske samfund, var der ikke tale om neutralitet, men det modsatte. Enhver social orden har sine vindere og tabere og en fastholdelse af en given orden er også en fastholdelse af givne vindere og givne tabere. Gouldner skrev bl.a.:

Underlying the formal conception of "social order in general" is a tacit, concrete image of a specific order with its fixed distribution of life changes. The quest for order is thus an ideology; it congenially resonates sentiments that favour the preservation of privilege. And it is a very persuasive one too, for it speaks on behalf of an imputed common interest shared 
by the privileged and disadvantaged alike, and it thereby presents itself as nonpartisian. But it neglects to mention that, while the interest is a common one, it is not .... an equal one. Some gain and or lose more than others when order breaks down; that, in some parts, is why it does break down. A social theory that takes as its central problem the maintenance of social order is thus more ideological congenial to those who have more to lose (Gouldner 1970:253-254).

Sociologer - som fx Gouldner - begyndte i stigende omfang at sætte spørgsmålstegn ved idealet om, at sociologien skulle ligne naturvidenskaberne. Og de satte spørgsmålstegn ved sociologiens professionalisering og professionsorientering. Sociologien skulle i stedet være fortolkende og indskrevet i et kritisk teoretisk univers, der satte spørgsmålstegn ved eksisterende sociale mønstre.

Forandringerne i 1968 betød også, at Marx kom på dagsordenen i amerikansk sociologi. Fra tidligere ikke at have optrådt som en del af sociologisk curriculum, blev Marx udnævnt til en af sociologiens fædre. "In the early 1970s, Marx was unexpectedly added to the list of central figures in sociology" (Hamilton 2003:285).

1968 og kritikken af ASA handlede dog ikke kun om samfundsforandringer, men implicerede også forsøg på at positionere nogle universiteter frem for andre. Sociologien havde i løbet af 1950'erne manifesteret sig som en øst-kyst disciplin i tilknytning til universiteterne Harvard og Columbia. Opgøret med "mainstream" sociologien - i form af Parsons' strukturfunktionalisme-bragte andre universiteter og sociologiske afdelinger på banen. Blandt andet i Californien, hvor man kunne vinde prestige gennem udviklingen af en mere progressiv sociologisk profil. Calhoun \& Truster skriver:

Despite a history of dissent and diversity, sometime around 1970 sociologists began to refer to an illusive phenomenon called "mainstream sociology". The mainstream was typified by the ASA leadership, by the American Sociological Review, and by a few elite departments like those at Harvard and Columbia. It was more East Coast than West Coast, and some influential West Coast sociology departments achieved stature and derived glamour from appearing insurgent (Calhoun \& Truster 2005: B7).

\section{Kvinder i amerikansk sociologi - og den anden Weber}

Før 1960'erne optrådte kvinder stort set ikke i amerikansk sociologi hverken som forskere eller som studieobjekter. Det er naturligvis et overdrevet udsagn, men alligevel med et vist indhold af sandhed. Før 1968 var sociologien først og fremmest præget af hvide mænd. Ikke at situationen er komplet forandret $\mathrm{i}$ forhold til i dag, men kvinder spiller en betydelig større rolle både som forsknings-"objekter" og forskere/undervisere. 
Kvindernes indtog i amerikansk sociologi har også sat fokus på en række af de kvinder, som har arbejdet inden for den sociologiske profession, men som er blevet glemt af den sociologiske fortælling om sin egen historie. En af disse er "den anden Weber", som det blev formuleret på et seminar på ASA-kongressen af Gillian Niebrugge og Patricia Lengermann fra henholdsvis American University og Georg Washington University ${ }^{6}$ (session 522).

Den første Weber kender alle med en vis sociologisk viden. Det er Max Weber. Den anden Weber, kender dog kun de færreste. Det er Max Webers kone (og kusine), Marianne Weber der, ud over at være gift med Max Weber, selv udfoldede sig som sociolog omkring århundredeskiftet $i$ Tyskland. Weberkendere vil vide af Marianne Weber, dels fra hendes omfattende biografi om Max Weber, dels fra hendes arbejde med at få samlet og kommenteret det, der blev udgivet som "Wirtschaft und Geshellschaft" efter Max Webers død. Men derudover er det småt med kendskabet.

Ud over den sociologiske kvalitet $\mathrm{i}$ arbejderne om hendes mand, var det dog især Mariane Webers selvstændige forskningsindsats, der blev fremhævet af Lengermann og Niebrugge. Ikke mindst bogen Wife and Mother in the Development/Evolution of Law (Ehefraus und mutter in der rechtsentwicklung (1907)) blev fremdraget som eksempel på et tidligt feministisk studie, hvor fokus først og fremmest var på analysen af kvinders rolle og placering i ægteskabet og $\mathrm{i}$ samfundet. Og med vægt på både lange historiske linier og på - på daværende tidspunkt - aktuelle observationer omkring kvindens rolle og erfaringer i det tyske samfund.

Fru Weber havde på samme måde som Hr. Weber blik for kapitalismens samfundsforandrende potentiale. For Marianne Weber var det især muligheden for, at kapitalismen kunne skabe rum for kvinders selvstændige forsørgelse gennem lønarbejde og derigennem frigørelse fra hjemmet, der var i centrum for analysen.

At Marianne Webers arbejde vakte opmærksomhed i samtiden, vidnede anmeldelserne om. Her brugte en anden ganske kendt sociolog - Emile Durkheim - hele seks sider på at anmelde bogen. Om end en ganske kritisk anmeldelse, der især - i følge Niebrugge og Lengermann - beklagede Marianne Webers manglende forståelse for familiens funktionelle rolle i det moderne samfund og for kvindernes placering heri.

\section{Videnskabeliggørelse af de kvalitative analyser}

Hvad er det for krav, det sociologiske samfund mødes med? Og hvilke tendenser kan der aktuelt lokaliseres i sociologien? Et af dem vedrører videnskabeliggørelse. Barbara Schneider, professor på University of Chicago (session 12), lokaliserede i relation til sine egne erfaringer med uddannelsesforskning, hvordan forskningen mødes med flere og flere krav om at følge særlige videnskabelige koder for tilrettelæggelse af undersøgelsesdesign. Det gør sig især gældende i forhold til de kvalitativt tilrettelagte studier. Kvalitative studier under- 
lægges i stigende omfang - $\mathrm{fx}$ fra de amerikanske forskningsråds side - krav om reproducerbarhed. Et krav der er velkendt i kvantitative studier, men som ofte er blevet betragtet som meningsløst i en mere kvalitativ kontekst.Det er i høj grad spørgsmålet om de kvalitative studiers udsagnskraft og repræsentationsstyrke, der er baggrunden for de mere massive krav om videnskabeliggørelse af de kvalitative studier. Kravene sigter på, at analyser, der baserer sig på kvalitative data, i højere grad bliver i stand til at etablere resultater, der har et højere generaliserbarhedsniveau, end (nogle mener) tilfældet er nu.

Derfor peger Schneiders iagttagelser i retning af, at der i stigende omfang udvikles standarder og koder for, hvordan kvalitative studier skal udføres, i fald de skal kunne falde ind under kategorien "sociologisk videnskab". Det kan fx dreje sig om randomisering af, hvilke interviewpersoner der skal deltage i et givent videnskabeligt projekt. Eller det kan dreje sig om krav om udveksling af data. Kvalitative data tenderer ofte til at cirkulere i snævre kredse og når sjældent ud over de forskere, der er involveret i dataindsamlingen. Årsagerne er mange, dels er det en tradition, dels er der en tendens til, at forskere holder deres data tæt ind til kroppen. De etiske principper i ASA fastslår dog generelt, at forskningsmateriale skal være offentligt tilgængeligt, når en given undersøgelses resultater er blevet publiceret. Og det gælder både kvantitative og kvalitative data. Som Schneider påpegede, er det langt fra alle sociologer, der vil råbe hurra for de skitserede udviklingstendenser, men presset er der alligevel.

\section{Sociologi mellem videnskab og samfund}

Hvor nogle - jf. ovenfor - iagttog tendenser til og pres i retning af øget videnskabeliggørelse og specialisering inden for den sociologiske disciplin, fandt andre, at sociologien mere har behov for øget interaktion med det omgivende samfund. Gruppen "Sociologists without boarders", der var repræsenteret på en række seminarer på kongressen, slog til lyd for det sidste (session 165). Her var synspunktet, at sociologien i for ringe omfang forholder sig til de problemer, det amerikanske samfund står overfor. Alberto Moncada fra "Sociologist without boarders" argumenterede for, at sociologien som disciplin var blevet for optaget af problemstillinger, der kun i begrænset omfang havde offentlighedens interesse, og som kun i begrænset omfang kunne bidrage til løsning af det amerikanske og det internationale samfunds problemer. Sociologiens manglende evne til at gribe og analysere aktuelle sociale begivenheder (og katastrofer), blev da også fremhævet flere gange. Sociologer har fx kun i meget begrænset omfang forholdt sig til efterspillet omkring Tsunamien i Asien, selvom opbygningen og forandringerne i de berørte samfund på en gang giver mulighed for, at sociologien kan bidrage med ekspertise i forhold til de berørte samfund og samtidigt lave analyser af ekstreme, sociale forandringsprocesser.

Også formanden for det samfundsvidenskabelige forskningsråd i USA, Pro- 
fessor Craig Calhoun fra New York University har slået til lyd for, at sociologien oparbejder en mere klar og involverende profil i offentligheden og har i det hele taget diskuteret sociologien i relation til det offentlige domæne.

Public social science does not equal applied social science. More "applied" research may be helpful, but the opposition of applied to pure is itself part of the problem. It distracts attention from the fundamental issues of quality and originality and misguides as to how both usefulness and scientific advances are achieved. Sometimes work undertaken mainly out of intellectual curiosity or to solve a theoretical problem may prove practically useful (Calhoun 2004:12).

\section{Rigtige kvindeforskere skriver alene - sociologi om sociologien}

Rigtige kvindeforskere skriver og publicerer alene. Til gengæld skriver matematisk orienterede sociologer sammen med andre. Og forskere med interesse i sociologisk teori, eller som er marxister, publicerer alene, mens velfærdsforskere skriver sammen. Sådan er det ikke altid, men der er noget om snakken. Det viser en række videnssociologiske analyser af faglige fællesskaber $i$ amerikansk sociologi, der blev præsenteret på kongressen (session 592) (Moody 2004).

Det er særligt de kvantitativt orienterede studier inden for sociologien, der er karakteriseret ved, at forskerne skriver sammen. Årsagerne kan være mange. Dels at kvantitative analyser er blevet så komplicerede, at det ofte er nødvendigt for den ikke matematisk sagkyndige at arbejde sammen med en statistisk ekspert. Dels lægger kvantitative studier sig ofte tættere på de naturvidenskabelige koder for videnskabelig praksis i almindelighed. Og her er medforfatterprincippet særdeles udbredt. Omvendt er kvalitativt eller teoretisk orienterede artikler ofte publiceret med enkelte forfattere. Måske fordi det de facto er sværere at dele arbejdsopgaverne mellem sig i forskningsprocessen. Måske fordi det i højere grad er en tradition i de humanistiske videnskaber. I hvert fald: Jo tættere sociologien er på humaniora, jo mere arbejdes der alene. Jo tættere på naturvidenskaberne, jo mere arbejdes der i forskerteams.

Trods de forskellige forventninger og krav til sociologien om på den ene side at optræde mere "naturvidenskabeligt" og på den anden side vende sig mere mod samfundet, var det et gennemgående synspunkt på en række af kongressens seminarer, at sociologiens genstandsfelter grundlæggende er konstitueret med udgangspunkt i en problemorienteret tilgang til samfundet. Det er samfundsmæssige problemer, der-hvordan de så end konstrueres - er afgørende for de emner, der tages op i sociologien. 


\section{Grand Theory}

Spørgsmålet melder sig: Hvem er det amerikanske svar på Anthony Giddens? Eller det amerikanske svar på Niklas Luhmann? Hvem formulerer de store teorier om samfundets udvikling og betingelserne for menneskelig handlen og adfærd. Svaret blafrer lidt i vinden som Bob Dylan sang, dengang Parsons endnu herskede på Harvard.

Den videnskabelige specialisering er til gengæld markant. Amerikansk sociologi består af et væld af specialiserede subdiscipliner, der hver især har deres eget teoretiske fundament og hvert deres tidsskrifter. Som en af de yngre sociologer på kongressen James Moody, fra Ohio State University, formulerede det $\mathrm{i}$ en seminargruppe om vidensakkumulation i sociologien (session 592):

Jeg ved meget om netværkssociologi og lidt mindre om matematisk sociologi. Jeg bilder mig ind, jeg ved, hvad der er det teoretiske grundlag i de to discipliner. Hvornår der bliver sagt noget nyt og hvornår noget, der formuleres som noget nyt, reelt er sagt før. Men kvindestudier? Ingen anelse.

Måske er det ikke længere muligt, at et enkelt princip - hvad enten det så er autopoesis, strukturation eller noget helt tredje - meningsfuldt kan siges at kunne rumme indgangen til formuleringen af teorier inden for hele den sociologiske disciplin. Måske er tiden, hvor sociologer må acceptere, at specialiseringen er så massiv, at det i bedste fald er Mertons tale om "middle range theory", der kan blive tale om. Hvem ved? Under alle omstændigheder er det interessant at stifte bekendtskab med amerikansk sociologi.

\section{Noter}

1. Mead publicerede kun i begrænset omfang selv i sin karriere. De fleste af Meads bøger ( $f x$ Mead 1934) er udgivet efter hans død på baggrund af forelæsninger og mindre artikler (Swingewood 1991: 263).

2. Som i øvrigt 'opfandt' begrebet symbolsk interaktionisme.

3. Session 249 refererer til sessionsnummeret på ASA kongressen, se American Sociological Association (2005).

4. En række indlæg på kongressen (Session 88) var koncentreret omkring amerikansk sociologis historie og baserede sig på en bog, der forventes udgivet på University of Chicago Press, redigeret af Craig Calhoun med titlen "Sociology in America - the ASA centennial history“. Heri behandles emner som kvinder i sociologien, sociologien under 2. verdenskrig, sociologiens udvikling som videnskabelige identitet o.m.a.

6. En anden glemt historie, der involverer kvinder i sociologien omhandler kvindelige sociologer i det sydlige USA jf. Broschart (2005).

\section{Litteratur}

Oplæg fra de omtalte oplægsholdere ved ASA's 100 års kongres, 12-16. august, 2005, i Philladelphia, Pensylvenia, USA. 
American Sociological Association 2005: Final Program, Comparative Perspectives, Competing Explanation - Accounting for the Rising and Declining Significance of Sociology. New York: ASA.

Blasi, A. J. (ed.) 2005: Diverse Histories of American Sociology. Boston: Brill.

Broschart, K. R. 2005: “The Neglected Contribution of Female Sociologists in the American South", in Blasi (ed.): Diverse Histories of American Sociology. Boston: Brill.

Calhoun, C. and Duster, T. 2005: "The Vision and Division of Sociology". The Cronicle Review, 2005, 49: B7.

Calhoun, C. 2004: "Toward a more Public Social Science". Items and Issues, 5, 1-2: 12-15.

Deegan, M. J. 2005: “A Private Trouble Behind the Gendered Divsion of Labor in Sociology: the Curious Marriage of Robert E. Park and Clara Cahill Park" in Blasi (ed.): Diverse Histories of American Sociology. Boston: Brill.

Gouldner, A. W. 1970: The Coming Crises of Western Sociology. London: Heinemann.

Hamilton, R. F. 2003: "American Sociology Rewrites its History", in Sociological Theory, 2003, 21, 3:281-297.

Hill, M. R. 2005: Centennial Bibliography on the History of American Sociology. Washington D.C.: American Sociological Association.

Lengermann, P., \& Niebrugge-Brantley, J. 1998: The Women Founders: Sociology and Social Theory 1830-1930. New York: McGraw-Hill.

Mead, G.H. 1934: Mind, Selfand Society. Chicago: University of Chicago Press.

Moody, J. 2004: “The structure of Social Science Collaboration Networks: Disciplinary Cohesion from 1963 to 1999", in American Sociological Review, 2004, 69, 2:213-238.

Rosich, K. J. 2005: A History of the American Sociological Association, 1981-2004. Washington D.C.: American Sociological Association.

Rhoades, L. J. 1981: A History of the American Sociological Association 1905-1980. Washington D.C.: American Sociological Association.

Schwartz, M.A. 1987: "Historical Sociology in the History of American Sociology", in Social Science History, 1987, 11, 1:1-16.

Sibley, E. 1963: The Education of Sociologists in the United States. New York. Russell: Sage Foundation.

Smelser, N. J. 2000: "Sociological and Interdisciplinary Adventures: A Personal Odyssey", in American Sociologist , 2000, 31, 4:5-33.

Swingewood, A. 1991: A Short History of Sociological Thought, 2. ed.. Hong Kong: Macmillan Press LTD.

Vromen, S. 2005: “Chicago 1930: Maurice Halbwachs' Outsider View of the City and its Sociologists", in Blasi (ed.): Diverse Histories of American Sociology. Boston: Brill.

Weber, Marianne 1907: Ehefrau und mutter in der rechtsentwicklung . Tübingen: Mohr.

Weber, Marianne 1989: Max Weber-ein lebensbild. Piper.

Wright Mills 1956: The Power Elite. New York: Oxford University Press.

Wright Mills 1959: The Sociological Imagination. New York: Oxford University Press.

Carsten Strøby Jensen

E-mail:Carsten.S.Jensen@sociology.ku.dk 